\title{
$\mathrm{ASF}$ 예측치와 실측치 비교
}

\author{
신미영*· 황상욱**・유동희 $* * * \cdot$ 박찬식 $* * * * \cdot$ 이창복 $* * * * * \cdot$ 이상정 $\uparrow$
}

***, $\uparrow$ 충남대학교 전자공학과, ***부산가톨릭대학교 멀티미디어공학과 *****충북대학교 전자공학전공, *****한국표준과학연구원

\section{Comparison of Predicted and Measured ASF}

\author{
Mi-Young Shin* ·Sang-Wook Hwang** · Dong-Hui Yu*** · Chan-Sik Park**** \\ Chang-Bok Lee****** Sang-Jeong Lee ${ }^{\dagger}$ \\ $*, * *,+$ Department of Electronics Engineering, Chungnam National University, Korea \\ *** Department of Multimedia Engineering, Catholic University of Pusan, Korea \\ **** Department of Electronics Engineering, Chungbuk National University, Korea \\ ***** Time and Frequency Group, Korea Research Institute of Standard and Science, Korea
}

\begin{abstract}
요 약 : 대부분의 응용분야에서 GNSS가 주 측위 시스템으로 활용되고 있으나, 방해전파에 대한 취약성으로 인해 최근에 몇몇 국가에서 eLoran 시스템을 GNSS 백업용으로 사용하기 위한 연구를 진행 중이다. eLoran 시스템의 구축을 위해서는 기존 Loran 시스템에서 설비의 업 그레이드, 데이터 채널 사용, dLoran 사이트 추가 구성, 전파 지연오차 보상을 통한 성능 향상이 필요하다. eLoran 신호를 이용한 측위 시에 정확도 성능에 가장 큰 영향을 미치는 오차요소는 육지를 통해 전파될 때 겪는 부가적인 지연요소인 $\mathrm{ASF}$ 이다. ASF는 지상파 신호가 전파 시에 가변적인 고도, 유전율, 도전율 특성을 갖는 육지를 통과하며 발생하는 지연요소이다. 따라서 지상파를 이용한 항법 시에 ASF에 대한 보상모델을 설정하는 것은 매우 중요하다. 본 논문에서는 몬테쓰 모델 (Monteath's Model)을 사용하여 ASF 예측치를 모델링하고, Loran 신 호를 이용한 실측을 통해 ASF 실측치를 측정한 후, ASF 예측치와 실측치를 비교하고 특성을 도출하였다. 실험대상 지역은 대전 KRISS와 포항 근방이며, GRI 9930 체인 중 주국인 포항 송신국의 신호를 사용하였다. 실험을 통해 ASF 실측치의 반복성을 확인하고, ASF 예측치와 실측치 간에 일정한 추이를 보이는 것을 확인하였다.
\end{abstract}

핵심용어 : eLoran, 전파지연오차, $\mathrm{ASF}, \mathrm{ASF}$ 예측치, $\mathrm{ASF}$ 실측치, $\mathrm{ASF}$ 에 의한 시간상의 편차, $\mathrm{ASF}$ 에 의한 공간상의 편차

Abstract : In the almost application parts, GNSS being used the primary navigation system on world-widely. However, some of nations attempt or deliberate to enhance current Loran system, as a backup to satellite navigation system because of the vulnerability to the disturbance signal. Loran interests in supplemental navigation system by the development and enhancement, which is called eLoran, and that consists of advancement of receiver and transmitter and of differential Loran in order to increase the accuracy of current Loran-C. A significant factor limiting the ranging accuracy of the eLoran signal is the ASF in the TOAs observed by the receiver. The ASF is mostly due to the fact that the ground-wave signal is likely to propagate over paths of varying conductivity and topography. This paper presents comparison results between the predicted ASF and the measured ASF in a southern east region of Korea. For predicting ASF, the Monteath model is used. Actual ASF is measured from the legacy Loran signal transmitted Pohang station in the GRI 9930 chain. The test results showed the repeatability of the measured ASF and the consistent characteristics between the predicted and the measured ASF values.

Key words : eLoran, Propagation delay error, ASF, Predicted ASF, Measured ASF, Temporal ASF, Spatial ASF

\section{1. 서 론}

2001년에 미국의 Volpe社 NTSC (National Transportation Systems Center)의 평가 보고서인 Volpe(2001)에서 방해전파 에 대한 $\mathrm{GPS}$ 의 취약성이 제기되었고, 이에 대비한 백업용 항 법 시스템으로 현대화된 Loran 시스템(eLoran : Enhanced
Loran)의 적합성이 평가되었다. 이후에도 백업 시스템의 필요 성은 꾸준히 요구되었으며, 이에 따라 2002년 이후부터 미국과 유럽에서 Loran 시스템의 현대화를 위한 기초연구를 진행하였 다. 고주파, 저전력 특성을 갖는 위성항법시스템인 GPS와는 다르게 Loran은 저주파, 고전력 특성을 갖는 지상파항법시스 템으로 좋은 안정도 및 반복 정확도, 간섭에의 강인성을 갖는

\footnotetext{
* 대표저자 :정회원, snyh80@gmail.com 042)825-3991

** 정회원, zcgizer@cnu.ac.kr 042)825-3991

****정회원, dhyu@cup.ac.kr 051)510-0643

***** 정회원, chansp@chungbuk.ac.kr 043)261-3259

****** 정회원, cblee@kriss.re.kr 042)868-5140

† 교신저자 : 정회원, eesj1@cnu.ac.kr 042)821-6582
} 
다. eLoran은 GPS의 취약점 보완을 위한 백업 시스템으로 적 합할 뿐만 아니라, GPS/eLoran 통합 형태로 사용함으로써 더 나은 정확도, 유효성, 연속성을 얻을 수 있을 것으로 예상된다. 따라서 최근에는 eLoran 단독 항법 시에 성능개선을 위한 연 구 및 GPS/eLoran 시스템 통합을 위한 연구가 활발히 진행되 고 있다. 위와 같은 성능향상이 가능하다면 우리나라 입장에서 eLoran 시스템은 GPS 백업을 위한 목적뿐만 아니라 독자 항 법 시스템 구축을 위한 목적으로도 충분한 연구 가치가 있다. 현재 국내에는 Korea 체인 (GRI-9930) 중에 포항과 광주에 송 신국 2국을 운용 중에 있으며, 아직 독자 항법 시스템을 보유 하지 못한 우리나라 입장에서 이는 eLoran을 이용한 독자 항 법 시스템 구축 시에 큰 이점으로 작용할 것이다. 따라서 국내 환경에서 eLoran 시스템의 적합성 평가와 eLoran을 이용한 측 위 기술 개발 및 개선은 중요한 연구 이슈이다(국 등, 2005).

eLoran을 이용한 항법 시에 요구 성능은 해안지역에서 HEA (Harbor and Entrance Approach)를 만족하는 것이다. 요구 성 능을 만족하기 위해서는 지상파항법시스템에서 가장 큰 오차 요인으로 작용하는 ASF (Additional Secondary Factor)의 보 상이 절대적으로 필요하다. 최근까지도 미국의 USCG (United States Coast Guard)와 영국의 GLA (General Lighthouse Authorities) 등에서 $\mathrm{ASF}$ 보상을 위한 연구를 활발히 진행하 고 있으며, 2000년도 초까지는 Last et al.(2000), Johnson et al.(2003)에 의해 전파지연 모델 및 $\mathrm{ASF}$ 예측 모델을 이용한 보상 방법이 연구되었고, 2004년도 이후부터는 Johnson et al.(2007), Kuhn et al.(2006)에 의해 ASF 실측치를 이용한 보 상 방법이 연구되었다. $\mathrm{ASF}$ 예측 모델은 전파환경에 따른 시 변영향을 반영하기 어려운 단점이 있는 반면에 실측을 위한 수고를 덜 수 있으며, $\mathrm{ASF}$ 실측치를 이용한 경우에는 예측 모 델에 비하여 정확한 반면에 실측 데이터의 운용 및 적용, 실측 이 어려운 구역에 대한 처리안 등의 문제가 있다. 본 논문에서 는 국내 특정 지역을 대상으로 $\mathrm{ASF}$ 예측치 및 실측치의 특성 을 비교·분석하고, $\mathrm{ASF}$ 보상을 위한 측정치의 적합성을 판단 하였다. 본 논문은 2 장에서 eLoran 신호의 전파 지연오차 요인 을 분석하고, 3장에서는 $\mathrm{ASF}$ 예측 모델을, 4장에서는 $\mathrm{ASF}$ 실 측 방법론을 소개한 후, 5 장에서 국내의 특정지역을 대상으로 $\mathrm{ASF}$ 예측치와 실측치를 비교하고, 6장에서 결론을 맺고자 한다.

\section{2. eLoran 신호의 전파 지연오차}

\section{1 eLoran 신호의 전파 지연오차 요인}

Loran은 장거리 무선항법시스템 중의 하나로 $100 \mathrm{kHz}$ 의 안 정된 저주파를 사용하며, 송신국으로부터 $2,200 \mathrm{~km}$ 이내의 사 용자에게 서비스를 제공하는 지상파항법시스템이다(포항·광주 해상무선표지소, 2008). Loran-C는 연안 및 대양수로를 대상으 로 $460 \mathrm{~m}$ 의 항법 정확도로 서비스를 제공하고 있다. 최근에 GPS 백업을 위한 Loran의 현대화가 연구 중이며, 기존 Loran 시스템에서 설비의 업그레이드, 데이터 채널 사용, dLoran 사 이트 추가 구성, 전파 지연오차 보상을 통해 항공분야의 비정
밀접근(NPA, Non Precision Approach)과 해상의 항만입항 및 접근 $(\mathrm{HEA})$ 요구 성능을 만족할 정도로 항법 성능이 개선될 것으로 예상된다(Volpe, 2001).

eLoran 신호를 이용한 항법 처리 알고리즘은 송신국으로부 터 수신기까지의 전파지연시간인 TOA (Time of Arrival) 측 정치를 사용한다. 그러므로 신호전파 시에 발생하는 전파 지연 오차는 측위오차로 반영된다. $\mathrm{HEA}$ 를 만족하도록 측위 성능을 향상하기 위해서는 발생할 수 있는 전파 지연오차를 분석하고, 제거 또는 보상하여야 한다. eLoran 신호의 오차요인은 Fig. 1 과 같다. 크게 송신국에서 발생하는 오차, 전파 전파 시에 발생 하는 지연오차, 수신기에서 발생하는 오차로 나눌 수 있다. 송 신국에서 발생하는 오차는 TOT에 의한 시각 동기 오차, 송신 기 내부 지연오차가 있다. 전파 전파 시에 발생하는 지연오차 는 지상파가 지면을 따라 전파하며 발생하는 지연오차, 재방사 나 외부 간섭에 의한 오차가 있다. 수신기에서 발생하는 오차 는 수신 안테나에 의한 오차, 수신기 내부 지연오차가 있다. eLoran 송신국에서 수신기까지 신호 전파 시에 발생하는 오차 중에서 항법 성능에 가장 큰 영향을 미치는 성분은 전파 전파 시에 발생하는 지연오차이다. 전파 전파 시에 발생하는 지연오 차는 대기 중에서의 전파 전송에 의한 PF (Primary Factor), 수면 위의 전파 전송에 의한 SF (Secondary Factor), 육지에서 의 전파 전송에 의한 $\mathrm{ASF}$ 로 나뉜다. 이 중에서 $\mathrm{PF}$ 와 $\mathrm{SF}$ 는 거 리에 따라 상수 특성을 갖기 때문에, 쉽게 모델링하여 보상할 수 있다. 반면에 $\mathrm{ASF}$ 는 지형 및 매질의 특성에 따라 영향을 받기 때문에 모델링이 쉽지 않다. 그러므로 $\mathrm{ASF}$ 의 보상여부는 eLoran 수신기의 항법 성능을 결정하는 주요 요인이다.

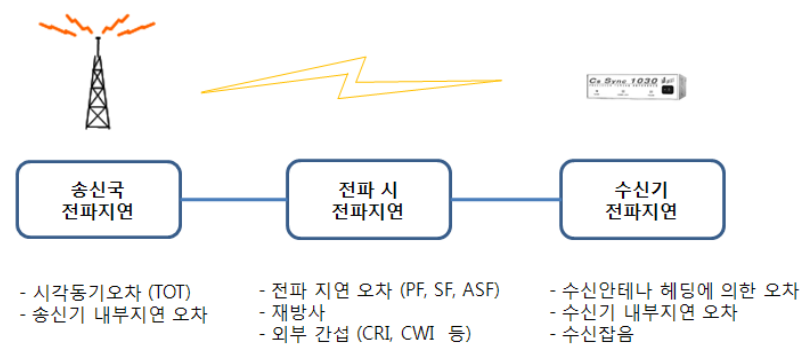

Fig. 1 Error sources of eLoran

\section{2 주요 오차 요인 : ASF 특성}

$\mathrm{ASF}$ 는 신호가 지면을 타고 전파되며 발생하는 부가적인 지 연 요소로 지형의 고도, 유전율, 전도율, 날씨 등에 영향을 받 는 가변적인 오차 요인이다. 전파가 지면상의 경로를 따라 진 행할 때, 지형의 불균일한 전도율, 다양한 고도각, 날씨에 의한 영향으로 전파지연이 발생한다. 습도나 온도와 같은 날씨 성분 은 전파 전파 시의 반사계수와 지대의 임피던스에 영향을 미 친다. $\mathrm{ASF}$ 는 전파거리의 환경요인에 의해 전파 전파 시에 수 백 미터의 지연오차를 발생시킬 수 있다. 기존의 Loran-C를 이용한 TDOA를 사용한 항법 시에는 $50 \mathrm{~m} \sim 460 \mathrm{~m}$ (1-sigma)의 정확도를 얻을 수 있었다면, eLoran을 이용한 TOA를 사용한 
항법 시에는 $\mathrm{ASF}$ 에 의한 공간상의 편차를 보상함으로써 $100 \mathrm{~m}$ 이내의 정확도를 얻을 수 있으며, 공간상과 시간상의 편 차를 보상함으로써 $\mathrm{HEA}$ 를 만족할 수준의 성능을 얻을 수 있 을 것으로 예상된다(Hartnett et al., 2004). 따라서 측위 정확도 의 개선은 $\mathrm{ASF}$ 를 얼마나 잘 보상하는지와 직결된다. 그러므로 $\mathrm{HEA}$ 를 만족하도록 측위 성능을 향상하기 위해서는 $\mathrm{ASF}$ 에 대 한 특성을 이해하고, 최적으로 보상하기 위한 안을 마련하는 것이 중요하다.

$\mathrm{ASF}$ 는 시간상과 공간상의 편차로 나누어 분석할 수 있다. 긴 시간 간격에 대하여 상수 형태를 갖는 공간상의 편차는 eLoran 신호의 전파 경로 상에서 균일하지 않은 전도율과 고 도의 변화에 의한 것으로 맵핑 방식을 사용하여 보상할 수 있 다(Luo et al., 2006). 짧은 시간 간격에 대하여 상수 형태를 갖 는 시간상의 편차는 날씨 변화에 의한 것으로 실시간 보정정 보를 사용하여 보상할 수 있다(Luo et al., 2006). 따라서 공간 상의 편차를 보상하기 위하여 ASF 보정맵 생성 및 저장 공간 이 필요하고, 시간상의 편차를 보상하기 위하여 실시간 보정정 보 생성 및 전송을 위한 데이터 링크가 필요하다.

$\mathrm{ASF}$ 에 의한 공간상의 편차를 보상하기 위한 $\mathrm{ASF}$ 보정맵을 생성할 때의 측정치로 $\mathrm{ASF}$ 모델링을 이용한 예측치나 실측을 통한 $\mathrm{ASF}$ 실측치의 장시간 평균값을 사용할 수 있다. ASF 예 측치는 실제 전파환경에 따른 영향을 반영하기 어려운 단점이 있는 반면에 $\mathrm{ASF}$ 보정맵 생성이 간단하고, $\mathrm{ASF}$ 실측치는 실 제 전파환경에 가장 유사한 보정치를 생성할 수 있지만 데이 터 실측을 위한 운용 및 적용, 실측이 어려운 구역에 대한 처 리안 등의 문제가 있다. 따라서 ASF 예측치와 실측치의 비교. 분석을 통해 $\mathrm{ASF}$ 보정맵 생성을 위한 측정치의 결정이 필요 하다. 이를 위해 본 논문에서는 국내 특정 지역을 대상으로 $\mathrm{ASF}$ 예측치와 실측치의 특성을 비교·분석하고, 이를 토대로 $\mathrm{ASF}$ 보상을 위한 측정치의 적합성을 판단하고자 한다.

\section{3. 몬테쓰 모델을 사용한 ASF 예측}

몬테쓰 모델 (Monteath's Model)은 전도율과 고도에 대한 정보를 토대로 송신국으로부터 수신기까지의 전파 지연 거리 에 따른 위상지연 및 신호감쇄를 모델링한 알고리즘으로 송신 국으로부터 반경 $1,000 \mathrm{~km}$ 이내의 사용자가 $\mathrm{ASF}$ 를 예측하기 위한 최적의 모델로 알려져 있다. 따라서 $\mathrm{ASF}$ 예측치를 도출 하기 위하여 몬테쓰 모델을 사용하였고, 지면 상태는 불규칙 지형 모델(Irregular terrain model)이라는 조건하에 수행하였 다. 정확한 $\mathrm{ASF}$ 를 모델링하기 위해서는 정확한 지표의 전도율 정보, 해안선 정보, 고도 정보를 보유해야한다. 본 논문에서는 몬테쓰 모델의 입력 파라미터로서 전도율은 ITU-R P.832.3(1992)에서 제공하는 남한 전도율 데이터를 사용하였고, 도엽은 NASA (2009)의 STRM에서 지원하는 $30 \mathrm{~m}$ 간격의 DEM (Digital Elevation Model) 정보를 사용하였으며, DEM 정보로부터 국내 남한 지역을 대상으로 해안선 정보를 도출하 여 사용하였다.
전파신호의 진폭감쇄와 위상지연을 반영한 복소 감쇄 파라 미터 $G$ 는 식 (1)과 같이 정의한다(Last et al., 2000). 이 때, $Z_{A B}^{\prime}$ 는 송신기와 수신기사이의 불규칙한 지형과 불완전한 전 도(imperfectly conducting) 상태의 복소 상호 임피던스 (complex mutual impedance)이고, $Z_{A B}$ 는 완전한 전도 (perfectly conducting) 상태의 복소 상호 임피던스이다.

$$
G=\frac{Z_{A B}^{\prime}}{Z_{A B}}
$$

Fig. 2 와 같이 송신국으로부터 거리 $R$ 만큼 떨어진 지점에서의 몬테쓰 모델에 의한 복소 감쇄 파라미터 $G(R)$ 의 모델링 식은 식 (2)와 같다(Last et al., 2000; Monteath, 1978).

$$
G(R)=1-\sqrt{\frac{j \beta_{0}}{2 \pi}} \int_{0}^{R}\left(\Psi+\frac{\eta}{\eta_{0}}\right) e^{-j \xi} \sqrt{\frac{R}{r(R-r)}} G(r) d r
$$

여기서 $\Psi$ 는 Fig. 2 와 같이 불규칙 지형 경로에 의한 각도이고, $\xi=\beta_{0}[(A P)+(P B)-(A B)]$ 이다. $\beta_{0}$ 는 자유공간에서의 전파 상수로 $2 \pi / \lambda$ 이고, $\lambda$ 는 파장이다. $R=a \Phi$ 이고, $r=a \phi$ 이며, $a$ 는 지구의 반지름이고, $R$ 과 $r$ 은 $A P, P B, A B$ 의 거리를 이용 하여 얻을 수 있다. $\eta / \eta_{0}$ 는 지구의 상대적인 표면 임피던스로 $\eta / \eta_{0} \cong\left(\varepsilon_{r}+1\right)^{-1 / 2}$ 이고, $\varepsilon_{r}=k-j \times 1.8 \times 10^{10} \sigma / F$ 는 복소 상 대 유전율, $\sigma$ 는 지표 전도율, $F$ 는 주파수, $k$ 는 유전상수이다.

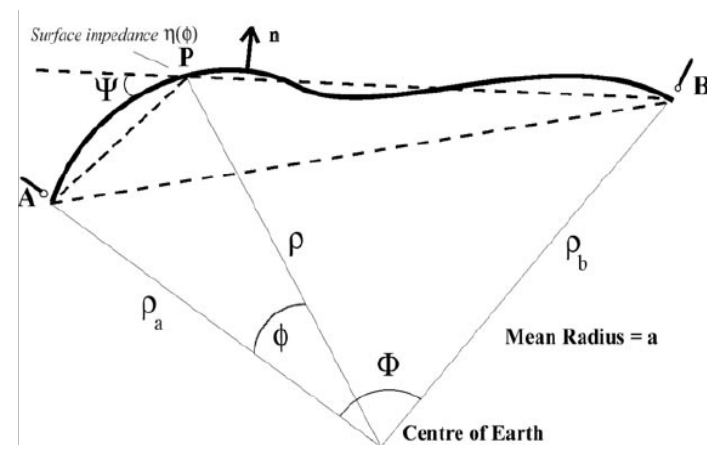

Fig. 2 Path geometry of Monteath' integral equation method

Loran과 같이 $100 \mathrm{kHz}$ 신호의 전파 시에 유전상수인 $k$ 는 육지 는 4 , 해양은 81 로 설정하였다. 몬테쓰 모델의 출력 $G(R)$ 로부 터 $\mathrm{ASF}$ 를 계산하기 위한 식은 식 (3)과 같다(Last et al., 2000).

$$
A S F(R)=G(R)_{\text {Mixed-path }}-G(R)_{\text {Salt-water }}
$$

여기서, $G(R)_{\text {Mixed-path }}$ 는 실제경로 상에서의 위상지연이고, $G(R)_{\text {Salt-water }}$ 는 전파 경로상의 재질이 해수라는 가정하에서 의 위상지연이다. 본 논문에서는 $G(R)_{M x e d-p a t h}$ 를 계산하기 위하여 ITU-R P.832.3으로부터 제공받은 지표의 전도율을 사 용하고, 유전상수 $k$ 는 육지에서 4 , 해양에서 81 로 설정하였다. 
$G(R)_{\text {Salt-water }}$ 을 계산하기 위하여 지표 전도율 $\sigma$ 는 $5,000 \mathrm{mS} / \mathrm{m}$ 로 설정하고, 유전상수 $k$ 는 81 로 설정하고, 전파 전파 경로는 지구타원체(smooth ellipsoidal earth) 모델이라고 가정하 였다. 그리고 모델링에서 적분간격 $r$ 은 $10 \mathrm{~m}$ 로 설정하였다.

\section{ASF 실측}

\subsection{TOA 측정 방법}

현재 국내에서는 eLoran 송신을 서비스하고 있지 않은 상황 이므로 송신국 간에 신호가 동기되어 있지 않고, 9930 체인의 주국인 포항 송신국은 TOC 서비스에 오류가 있어 UTC 동기 서비스를 제공하지 못하고 있다. 따라서 포항 송신국에서 서비 스 중인 Loran-C 신호를 수신하여 수신기의 원시 데이터로부 터 전파지연시간인 $\mathrm{TOA}$ 를 추출하고, $\mathrm{ASF}$ 를 도출하기 위한 별도의 측정 방법안이 필요하다.

본 논문에서는 전파지연시간인 $\mathrm{TOA}$ 를 실측하기 위하여 본 연구팀의 연구결과인 새로운 측정 방법을 사용하였다(Lee et al., 2009; Yang et al., 2009). Fig. 3과 같이 데이터 수집 환경 을 구성하고, $\mathrm{TOA}$ 계산을 위해 필요한 원시데이터를 수집하 였다. 원시 데이터를 수집하기 위하여, 사용자 수신기는 포항 송신국으로부터 송신된 Loran-C 신호에 락을 걸고, 수신신호 의 6 번째 제로-교차점을 추적한다.

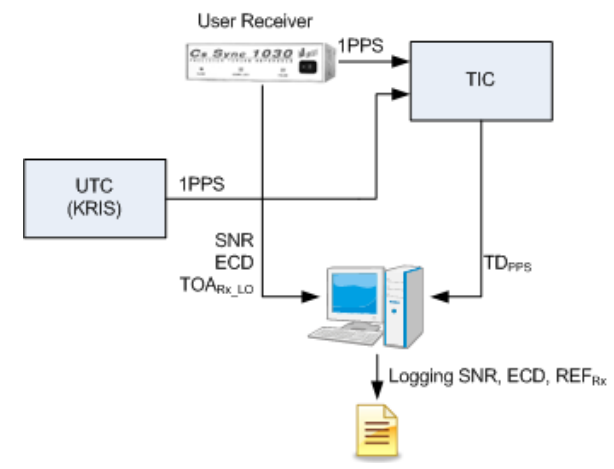

Fig. 3 Block diagram of the raw measurements collection scheme

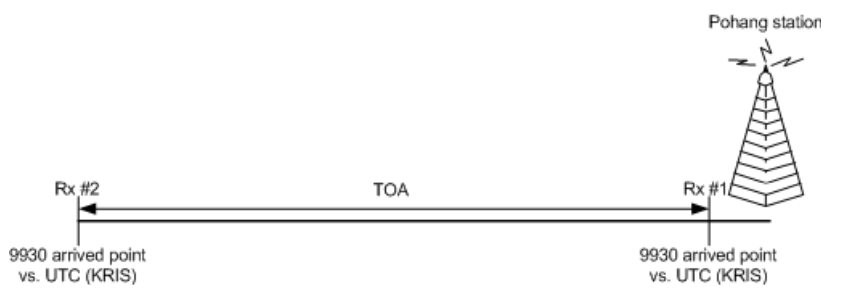

Fig. 4 Conceptional diagram of the TOA measurement

포항 송신신호의 펄스 그룹의 반복간격은 $99.3 \mathrm{~ms}$ 이다. 사용 자 수신기는 출력 파라미터로 $1 \mathrm{PPS}, \mathrm{SNR}, \mathrm{ECD}, \mathrm{TOA}$ 정보를 저장한다. 이 때, 수신기의 출력 파라미터인 TOA 정보는 송신 국으로부터 수신기까지 신호가 도착하는데 걸린 시간이 아닌
수신기의 내부 클럭을 기준으로 신호추적에 의한 변화량을 출 력한 것이다. 따라서 전파지연시간인 $\mathrm{TOA}$ 를 계산하기 위하여 사용자 수신기의 $1 \mathrm{PPS}$ 출력과 UTC(KRIS)의 $1 \mathrm{PPS}$ 출력 간의 차이인 $T D_{P P S}$ 와 수신기의 내부 클럭을 기준으로 신호추적에 의 한 변화량 $T O A_{R x_{-} L O}$ 를 사용하였고, $\mathrm{Loran}^{-\mathrm{c}}$ 수신기의 TOA 정보와 수신기에서 측정한 기준값 간의 관계는 식 (4)와 같다.

$$
\begin{aligned}
& R E F_{R x}=T D_{P P S}+T O A_{R x_{-} L O}= \\
& {\left[T_{U T C(K R I S)}-T_{R x_{-} L O}\right]_{1 P P S}+\left[T_{R x_{-} L O}-T_{T x_{-} U T C(\text { Loran })}\right]_{100 k H z}}
\end{aligned}
$$

측정한 수집 데이터로부터 전파지연시간인 $\mathrm{TOA}$ 를 계산하기 위하여 Fig. 4와 같이 UTC(KRIS)에 동기된 데이터 수집 장치 2 조를 송신국과 $\mathrm{ASF}$ 계산을 위한 수신 지점에 위치시키고 $R E F_{R x_{-} 1}, R E F_{R x_{-} 2}$ 를 수집한다. 두 지점에서의 $R E F_{R x}$ 측정치 를 사용하여 식 (5)와 같이 전파지연시간 $\mathrm{TOA}$ 를 측정하였다.

$$
T O A=R E F_{R x_{-}-2}-R E F_{R x_{-} 1}
$$

\subsection{ASF 측정 방법}

전파지연시간 $\mathrm{TOA}$ 는 식 (6)과 같이 표현할 수 있다. 여기서 $R R$ 은 실제거리이고, $T x_{d e l a y}$ 는 송신국에서의 지연 요소, $P D$ 는 전파 전파시의 지연 요소, $R x_{d e l a y}$ 는 수신기의 지연 요소, $w$ 는 측정 잡음이다. $P D$ 는 $P F, S F, A S F$ 로 구성되며, $\mathrm{ASF}$ 를 계산하기 위하여 이항하면 식 (7)과 같다.

$$
\begin{aligned}
& T O A=R R+T x_{\text {delay }}+P D+R x_{\text {delay }}+w \\
& A S F=T O A-R R-T x_{\text {delay }}-P F-S F-R x_{\text {delay }}
\end{aligned}
$$

시스템 성능개선 및 측정을 통해 $R R, T x_{d e l a y}, R x_{d e l a y}$ 를 계 산하고, Keating et al.(1986)이 제안한 $P F$ 모델과 Johler et al.(1956)가 제안한 $S F$ 모델을 적용하여 최종적으로 $\mathrm{ASF}$ 를 도 출하였다.

\section{ASF 예측치와 실측치 비교}

\section{1 실험환경}

$\mathrm{ASF}$ 보정맵을 생성할 때에 사용할 측정치의 적합성을 평가 하기 위하여 국내의 특정 지역을 대상으로 $\mathrm{ASF}$ 예측치 및 실 측치를 비교·분석하였다. Fig. 5와 같이 포항 송신국을 중심으 로 동일한 전도율과 고도 변화율이 적은 지역을 대상으로 한 단거리 실험영역과 전도율과 고도 변화율이 큰 지역을 대상으 로 한 장거리 실험영역으로 나누어 실험하였다. 장거리 실험은 포항 송신국으로부터 약 $180 \mathrm{~km}$ 떨어진 대전 KRISS에서 진행 하였고, 단거리 실험은 포항 송신국 근방으로 약 $35 \mathrm{~km}$ 이내의 9 지점에서 이동실험을 하였다. ASF 예측을 위하여 몬테쓰 모 델에서 불규칙 지형 모델을 사용하였고, 실측을 위하여 Loran 
타이밍용 수신기인 Cs Sync 1030 모델을 사용하여 데이터를 수집하였다. 실측실험 시에 전파환경에 따른 시변영향을 최대 한 배제하기 위하여 Johnson et al.(2007)과 Kuhn et al.(2006) 에서 제시한 바와 같이 $\mathrm{ASF}$ 의 편차가 작은 여름을 대상으로 동일한 시간대 (오후)에 반복하여 실험을 진행하였다. 2 조의 동일한 수집 환경을 구성하고, 2009년 7월 8일, 9일, 15 일에 걸 쳐 3 회 반복 측정하고, 수집한 데이터 6 조의 평균값으로 추이 를 분석하였다.

[장거리 실험영역]

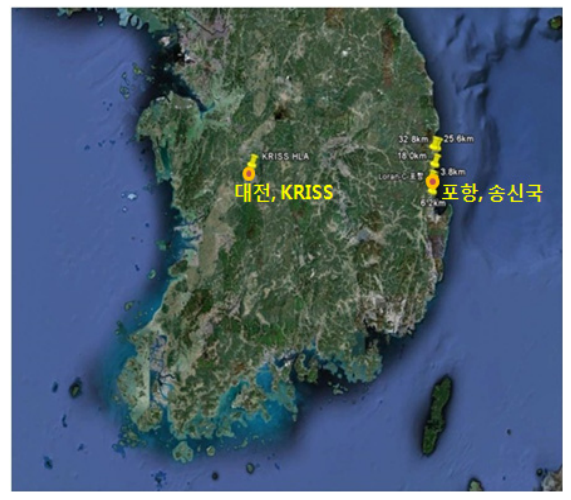

[단거리 실험영역]

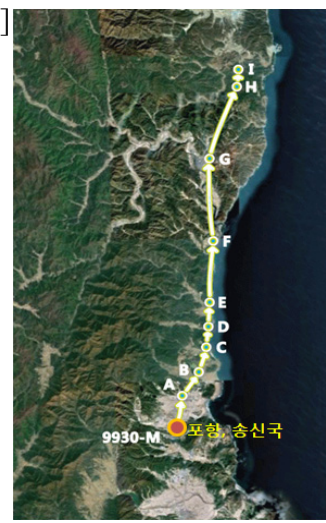

Fig. 5 Test regions

이 때, 한 조는 포항 근방에서의 센 송신전력에 의한 영향을 최소화하기 위하여 Loop 안테나를 사용하고, 다른 한 조는 $\mathrm{P}-$ static 영향을 최소화하기 위하여 $\mathrm{H}$-field 안테나를 사용하 여 측정 데이터를 수집하였다.

\section{2 실험결과}

단거리 실험영역을 대상으로 $\mathrm{ASF}$ 실측치를 분석한 그래프 는 Fig. 6과 같다. 포항 송신국을 중심으로 $35 \mathrm{~km}$ 떨어진 지점 까지 이동하며 9 지점에서 데이터를 수집하고, 6 조의 측정치의 최고값, 평균값, 최저값을 표시하였다. 포항 송신국으로부터 약 $180 \mathrm{~km}$ 떨어진 장거리 실험영역을 대상으로 한 대전 KRISS에 서의 $\mathrm{ASF}$ 실측치는 최고값 $3.842 \mu \mathrm{s}$, 평균값 $3.828 \mu \mathrm{s}$, 최저값 $3.812 \mu \mathrm{s}$ 를 갖는다. 실측을 통해 장거리, 단거리 실험에서의 측 정치가 대부분 $100 \mathrm{~ns}$ 이내로 반복성을 갖는 것을 확인하였다. 장거리 및 단거리를 대상으로 수집한 10 지점에서의 $\mathrm{ASF}$ 실
측치의 평균값과 몬테쓰 모델을 이용한 ASF 예측치를 비교한 결과는 Fig. 7과 같다. Fig. 7의 A 지점부터 I 지점까지의 단거 리 실험영역에서 $\mathrm{ASF}$ 예측치는 실측치보다 $0.7 \mu \mathrm{s}$ 이내의 차 이를 갖고 큰 것을 확인하였다. KRISS 지점의 장거리 실험영 역에서는 $\mathrm{ASF}$ 실측치가 예측치보다 $1 \mu \mathrm{s}$ 이내로 큰 것을 확인 하였다.

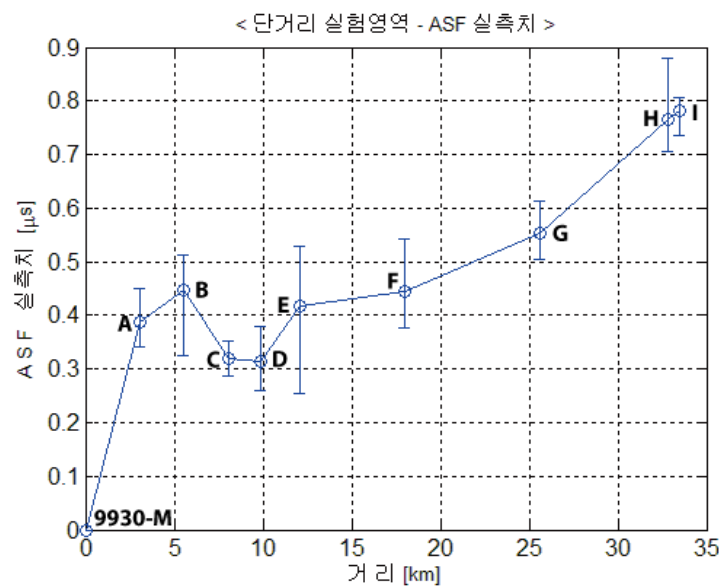

Fig. 6 Measured ASFs - Near the pohang station

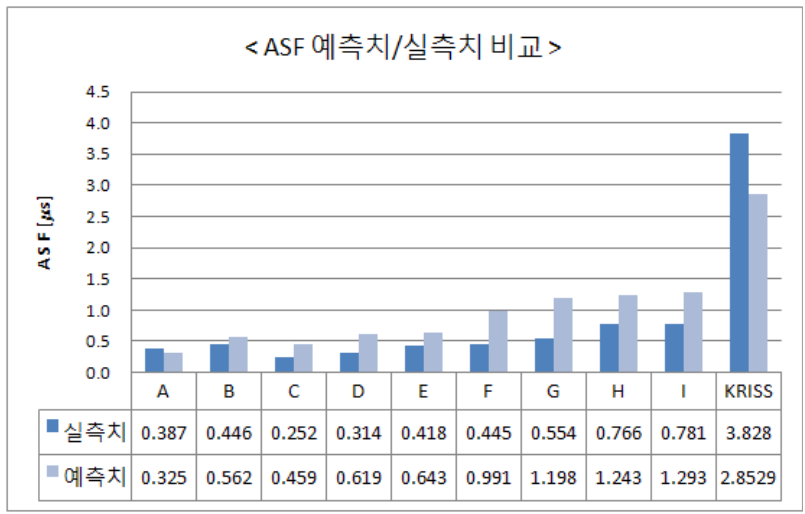

Fig. 7 Comparison of predicted and measured ASF

장거리, 단거리 실험에서 $\mathrm{ASF}$ 예측치와 실측치 간의 차이는 보유한 전도율 정보, 고도 정보의 분해능에 의한 영향으로 판 단된다. 또한 장거리 실험영역에서 $\mathrm{ASF}$ 실측치가 예측치보다 크게 발생한 것은 $\mathrm{ASF}$ 예측치는 모델링을 이용한 결과이므로, 장거리 실험영역에서 신호 전파 시에 실제 환경적 요인으로 인한 전파지연을 반영하지 못하기 때문으로 판단된다.

\section{6. 결 론}

$\mathrm{ASF}$ 예측치는 실제 전파환경에 따른 영향을 반영하기 어려 운 단점이 있는 반면에 $\mathrm{ASF}$ 보정맵 생성이 간단하고, $\mathrm{ASF}$ 실 측치는 실제 전파환경에 가장 유사한 보정치를 생성할 수 있 지만 데이터 실측을 위한 운용 및 적용, 실측이 어려운 구역에 대한 처리안 등의 문제가 있다. 따라서 $\mathrm{ASF}$ 예측치와 실측치 
의 비교·분석을 통해 $\mathrm{ASF}$ 보정맵 생성을 위한 측정치의 결정 이 필요하다. 본 논문에서는 $\mathrm{ASF}$ 보정맵을 생성할 때에 사용 할 측정치의 적합성을 판단하기 위하여 전파환경에 따른 시변 영향을 최대한 배제한 실험환경을 구성하고, 전도율 및 고도 변화율 특성에 따라 실험영역을 장거리와 단거리로 나누어, 특 정지역을 대상으로 $\mathrm{ASF}$ 예측치와 실측치를 분석하였다. 분석 을 통해 수집한 실측치가 $100 \mathrm{~ns}$ 이내로 반복성을 갖으며, 장거 리와 단거리 실험영역에서 각각 특정 오프셋을 갖고 비슷한 추이가 나타나는 것을 확인하였다. 아직 $\mathrm{ASF}$ 맵 생성 시에 사 용할 측정치를 결정하는 것은 섣부르지만, 실험결과를 통해 일 정한 특성을 도출할 수 있었다. 이를 통하여 $\mathrm{ASF}$ 맵 생성 시 에 특정 지점에 대하여 실측치를 사용하고, 실측이 어려운 구 역에 대하여 $\mathrm{ASF}$ 예측치를 활용하여 적용하는 것이 가능할 것으로 판단된다. $\mathrm{ASF}$ 맵 생성을 위한 측정치의 타당성을 얻 기 위해서는 추후로 전파지연시간인 $\mathrm{TOA}$ 측정 시의 오차를 최소화하고, 다양한 지역을 대상으로 한 추가 실험이 필요할 것으로 예상된다.

\section{참 고 문 헌}

[1] 국승기, 김정훈, 김민철(2005), "한국의 LORAN-C 정책방 향 수립에 관한 연구", 한국항해항만학회 제 29권 제 2호 추계학술대회논문집, pp. 163-168.

[2] "포항-광주 해상무선표지소 (2008), 기술마당, http://loran9930.go.kr/"

[3] Hartnett, C. R., Johnson, G., and Swaszek, P. (2004), "Navigation using an ASF Grid for Harbor Entrance and Approach", Institute of Navigation 60th Annual Meeting, pp. 200-210.

[4] ITU-R P.832-2 (1992), World ATLAS of Ground Conductivities, pp. 29.

[5] Johler, J.R., Kellar, W.J., and Walters, L.C. (1956), "Phase of the Low Radiofrequency Ground Wave", NBS Circular No. 573, pp. 1-38.

[6] Johnson, G., Hartnett, R., Swaszek, P., Moyer, T., and Shalaev, R. (2003), "Summer Vacation 2003 - ASF Spatial Mapping in CO, AR, FL, and CA", 32nd Annual Convention and Technical Symposium, International Loran Association.

[7] Johnson, G. W., Shalaev, J. R., Oates, C., Hartnett, C. R., and Swaszek, P. F. (2007), "4 Down, 50 to go - An Update on Harbor Surveys in the United States", 36th Annual Convention and Technical Symposium, International Loran Association.

[8] Keating, R.E., Lukac, C.F., Luther, G.H., and Charron, L.G. (1986), "Timing Calibration of the Northeast U.S.A Loran-C Chain(9960)", 18th Annual PTTI Applications and Planning Meeting, pp. 331-351.
[9] Kuhn, M., Johnson, G., Wiggins, M., Swaszek, P., and Hartnett, C. R. (2006), "Warping Time and Space : Spatial Correlation of Temporal Variations", 35th Annual Convention and Technical Symposium, International Loran Association.

[10] Last, D., Williams, P., and Dykstra, K. (2000), "Propagation of Loran-C signals in Irregular Terrain-Modelling and Measurements : Part I : Modelling", 29th Annual Convention and Technical Symposium, International Loran Association.

[11] Lee, C.B., Yang, S.H., Lee, Y.K., Suh, S.H., Shin, M.Y., and Lee, S.J. (2009), "An Assessment Method for eLoran Performance using the Legacy Loran Signal", ENC-GNSS 2009.

[12] Luo, N., Mao, G., Lachapelle, G., and Cannon, E. (2006), "ASF Effect Analysis Using an Integrated GPS/eLORAN Positioning System", Institute of Navigation National Technical Meeting 2006, pp. 967-976.

[13] Monteath, G.D. (1978), "Computation of Groundwave Attenuation over Irregular and Inhomogeneous Ground at Low and Medium Frequencies", BBC Report 1978/7, pp. 1-18.

[14] NASA (2009), SRTM, "http://www2.jpl.nasa.gov/srtm/" Volpe National Transportation Systems Center, US Department of Transportation, Office of Assistant Secretary for Transportation Policy (2001), Vulnerability Assessment of the Transportation Infrastructure Relying on the Global Positioning System, Volpe Report

[15] Yang, S. H., Lee, C. B., Lee, Y. K., and Lee, S. J. (2009), "Design of ASF Measurements System in the Field", International Symposium on GPS/GNSS 2009.

원고접수일 : 2010년 2월 22일

심사완료일 : 2010년 4월 7일

원고채택일 : 2010년 4월 9일 